\title{
Ergenlerde Okul Aidiyeti, Okul iş̧levleri ve Psikolojik Uyum Arasındaki ílișkinin İncelenmesi
}

\author{
Gökmen ARSLAN* \\ Ahmet TANHAN $^{* *}$
}

Öz: Bu çalışmada ergenlerde okul aidiyet duygusu, okul işlevleri ve psikolojik uyum arasındaki ilişki incelenmiştir. Araştırmanın örneklemini yaşları 11 ile 18 arasında değişen, ortaokul ve lisede öğrenci olan 333 ergen oluşturmaktadır (Ortalama = 15.45; ss = 1.75). Katılımcıların \%55.9'u (186) kız ve \%44.1'i (147) erkektir. Korelasyon analiz sonuçları, ergenlerde okul aidiyeti artarken içselleştirilmiş ve dışsallaştırılmış problemlerin azaldığını ve okul işlevlerinde de anlamlı bir artışı olduğunu ortaya koymuştur. Yol (path) analiz sonuçları, okul aidiyetinin öğrencilerin akademik başarı, öğrenmeden zevk alma, eğitimsel amaçlar, akademik yeterlik, akademik doyum ve prososyal davranımlarını pozitif yönde ve anlamlı düzeyde yordadığını göstermiştir. Ayrıca sonuçlar okul aidiyetinin ergenlerde içselleştirilmiş ve dışsallaştırılmış problemleri negatif yönde ve anlamlı düzeyde yordadığını ortaya koymuştur. Okul aidiyet duygusu, akademik başarı değişkeni hariç, diğer tüm değişkenler üzerinde güçlü bir yordayıcı etkiye sahip olduğu görülmüştür. Araştırma sonuçları alan yazın ışığında tartışılmış ve önerilerde bulunulmuştur.

Anahtar Sözcükler: Okul Aidiyeti, Psikolojik Uyum, Ergenlik, Ekolojik Sistemler Kuramı, Pozitif Psikoloji, Öz-Belirleme Kuramı, Kabul ve Kararlılık Terapisi

\section{Examining the Association between School Belonging, School Functioning, and Psychological Adjustment in Adolescents}

\begin{abstract}
In the present study, the researchers investigated the relationship among school belonging, school functioning and psychological adjustment problems for the adolescents in high schools. Sample of the study comprised of 333 adolescent students from middle and high school, with ranging in age between 11 and 18 years (Mean =15.45; SD=1.75). Participants were 55.9\% (186) female and $44.1 \%$ (147) male. Correlation analysis results revealed that school belonging increases while internalizing and externalizing problems decrease and there is a significant increase in school functions. Path analysis outcomes indicated that school belonging predicted students' school achievement, joy of learning, educational purpose, academic efficacy, academic satisfaction, and prosocial behaviors. Furthermore, the results demonstrated that school belonging significantly and negatively predicted internalizing and externalizing problems in adolescents. School belonging has a strong effect size on all other variables except for academic achievement. The results are discussed in light of the literature and suggestions are presented.
\end{abstract}

Keywords: School Belonging, Adolescence, Ecological Systems Theory, Positive Psychology, Self-Determination Theory, Acceptance and Commitment Therapy

* International Network on Personal Meaning, Toronto, Ontario, Canada, e-posta: gkmnarslan@gmail.com, ORCID: https://orcid.org/0000-0001-9427-1554

** Adıyaman Üniversitesi, Eğitim Fakültesi, Eğitim Bilimleri Bölümü, Adıyaman, Türkiye, e-posta: tanhanahmet3@gmail.com, ORCID: https://orcid.org/0000-0002-4972-8591 
Son yıllarda pozitif psikolojiye olan ilginin de artmasıyla, okul aidiyetinin öğrencilerin gelişim ve uyumları üzerindeki etkisi en önemli araştırma konularının birisi olmuştur. Okul, ergenin günlük yaşamında merkezi bir konumdadır ve ergen birey eğitim-öğretim sürecinde zamanının büyük bir bölümünü okul ortamında geçirir (Arslan ve Duru, 2017). Bu süreçte bazı öğrenciler okula yönelik daha olumlu duygular içerisindedirler ve kendilerini okulun bir parçası olarak görürler (Arslan, 2016). Öğrencinin okulda değerli olduğuna ve desteklendiğine ilişkin kendi algısı okul aidiyeti olarak kavramsallaştırılmaktadır (Goodenow ve Grady 1993; Osterman, 2000). Okul aidiyeti öğrencinin kendisini okulun anlamlı, önemli ve değerli bir parçası olarak hissetmesi ve görmesidir (Arslan ve Duru, 2017). Goodenow ve Grady'e (1993) göre okul aidiyeti okul ortamında öğrencinin okulda bulunan diğer bireyler tarafından (öğrenci, öğretmen, idareci gibi) kabul edilen, saygi duyulan, okuldaki süreçlere ve etkinliklere dahil edilen ve desteklenen biri olarak kendisini hissetmesi ve görmesidir. O'Neill (2009) okul aidiyetini bireyin kendisini değerli ve önemli gördüğü yaşantılar olarak tanımlamıştır. Bu tanımlardan hareketle okul aidiyeti, öğrencinin kendisini okul bağlamında bulunan diğer tüm kişiler tarafından artıları ve eksileri ya da başarı ve başarısızlıkları ile bir birey olarak saygı gören, kabul edilen, okula değer katan biri olarak görmesi veya algılaması olarak tanımlanabilir.

Yapılan çalışmalar okul aidiyetinin öğrencinin olumlu akademik, sosyal ve duygusal yaşantıları üzerinde önemli bir faktör olduğunu ortaya koymaktadır (Anderman, 2003; Arslan ve Duru, 2017; Deci ve Ryan, 1991; Goodenow, 1993; Goodenow ve Grady, 1993; Osterman, 2000). Bu duygu bireyin kendisini okulda önemli ve saygı duyulan biri olarak hissetmesi sonucunda oluşur (Booker, 2004). Son yıllarda okul aidiyetine ilişkin yapılan çalışmalarda Türkiye'de (Doğan ve Özdemir, 2019; Erdem, 2017; Özdemir, Sezgin, Şirin, Karip ve Erkan, 2010) ve dünyada (Kim, Furlong ve Dowdy, 2019; Korpershoek, Canrinus, Fokkens-Bruinsma ve de Boer, 2019; Phan, 2013) önemli bir artış yaşansa da okul aidiyetinin ergenlerin psikolojik uyumu ve okul işlevleri üzerindeki etkisine ilişkin çalışmaların sayısı, kapsamı ve özellikle de kuramsal alt yapıları açısından oldukça sınırlı kaldığı görülmektedir. Özellikle Türkiye'de okul aidiyetine ilişkin yapılan çalışmaların sınırlı olması, yeni çalışmaların önemini daha da arttırmaktadır. Bu nedenle bu çalışmada ergenlerde okul aidiyetinin okul işlevleri ve psikolojik uyumla olan ilişkisi ele alınmıştır.

\section{Okul Aidiyeti, Okul İşlevleri ve Psikolojik Uyum Problemleri}

Aidiyet duygusu, bireyin temel motivasyon kaynağı olarak tanımlanmakta ve birçok problemin aidiyet yoksunluğu nedeniyle ortaya çıktı̆̆ belirtilmektedir (Baumeister ve Leary, 1995). Deci ve Ryan (2000) insanın bireysel/intrapsişik sürecini ve kaynaklarını ön plana alan bir yaklaşımdan bakarak geliştirdikleri öz belirleme kuramında insanın psikolojik olarak sağlıklı olabilmesi ve içsel motivasyona sahip olup üretken olması için aidiyetin en temel üç bileşenden biri olduğu belirtilmiştir. Benzer şekilde insanın hem bireysel/intrapsişik yönünü hem de içinde büyüdüğü bağlamı/çevreyi göz önünde bulunduran kabul ve kararlılık terapisi de bireyin psikolojik sağlamlığını ve bulunduğu bağlamlarda (örneğin okul, ev, sosyal hayat) işlevsel/üretken olabilmesini, bireyin kendisini bulunduğu bağlam içerisinde koşullandırmasına ve bu bağlamda kendisini anlamlandırmasına bağlamış ve bunun çok önemli olduğunu vurgulamıştır (Hayes, Strosahl ve Wilson, 2012; Springer, 2012). Bireysel/intrapsişik bakış açısından doğan, özellikle de öz-belirleme kuramı, bu iki yaklaşıma ek olarak daha kapsayıcı ve bağlamsal bir kuram olan ekolojik sistemler kuramında da bireyin kendini bir yere ait hissetmesinin önemi vurgulanmakta ve bu kuram bireyi daha kapsayıcı ve bütüncül bir bağlamda ele almanın gereğinden bahsetmektedir (Bronfenbrenner, 1977). Bu yaklaşımlar aynı zamanda pozitif psikolojiye de vurgu yapmıştır. Pozitif psikolojinin Türkiye'de (Arslan, 2019a; Koç, 2017; Telef, 2017) ve dünyada (Kansky ve Diener, 2017; Stuntz, 2017; Sumi, 2017; Tanhan, 2019; Tanhan ve Francisco, 2019) yükselişte olduğu da düşünüldüğünde hem pozitif psikoloji hem de psikopatolojiyi ele alan bireysel ve bağlamsal/kapsamlı yaklaşımların beraber kullanılması araştırma ve uygulamalar için çok daha etkili sonuçlar üreteceği görülmektedir (Arslan, 2019a).

Alanyazın ve bu kuramsal çerçevelere dayanarak okul aidiyet duygusu yüksek olan öğrencilerin okul yaşantılarından daha olumlu sonuçlar elde etmeleri yani okul işlevlerini daha sağlıklı bir şekilde yerine getirmeleri beklenilebilir. Bu çalışmada okul işlevleri kavramı öğrencinin prososyal davranış sergileme, öznel olarak iyi bir ruh haline sahip olma, akademik doyum düzeyi ve akademik başarı olarak kavramsallaştırılmıştır. Yapılan çalışmalar okul aidiyetinin öğrencilerin okul işlevleri üzerinde önemli bir 
faktör olduğunu göstermiştir (Adelabu 2007; Babakhani, 2014; Booker 2006; Gillen-O’Neel ve Fuligni, 2013; Phan 2013). Bu araştırmacılar, okul aidiyetinin akademik başarı, akademik motivasyon ve okula devam gibi yaşantılar ile yakından ilişkili olduğunu ortaya koymuşlardır. Örneğin, Arslan (2016) aidiyet duygusu düşük olan öğrencilerin daha düşük akademik başarıya, eğitimsel amaçlara ve akademik öz-yeterliğe sahip olduklarını ifade etmiştir. Birçok çalışmada okul aidiyeti ve akademik başarı arasındaki ilişki üzerinde durulmuş ve akademik başarısı yüksek olan öğrencilerin, akademik başarısı düşük olanlara göre, aidiyet duygusunun daha yüksek olduğu belirtilmiştir (Anderman, 2003; Booker, 2006; Goodenow ve Grady, 1993; Pittman ve Richmond, 2007; Sarı, 2013). Arslan ve Duru (2017) yaptıkları çalışmada okul aidiyetinin öğrencilerin akademik öz-yeterlik ve öğrenmeden zevk alma gibi okul işlevleri ile ilişkili olduğunu rapor etmişlerdir. Diğer bir çalışmada ise okul aidiyet duygusu yüksek olan bireylerin akademik motivasyon ve amaçsal davranma düzeylerinin daha yüksek ve okul devamsızlık düzeylerinin daha düşük olduğu bulunmuştur (Sánchez, Colón ve Esparza, 2005). Ayrıca yapılan boylamsal çalışmalar okul aidiyetinin bireyin akademik öz-yeterlik, akademik başarı, motivasyon gibi okul işlevleri üzerinde etkili olduğunu ortaya koymuştur. Gillen-O'Neel ve Fuligni (2013) tarafından yapılan boylamsal bir çalışmada, okul aidiyetinin öğrencilerin akademik motivasyon ve başarıları üzerinde önemli rol oynadığı bulunmuştur. Benzer şekilde McMahon, Parnes, Keys ve Viola (2008) tarafından yapılan bir çalışmada, okul aidiyetinin öğrencilerin okul doyumu ve akademik öz yeterlik düzeylerinin önemli bir yordayıcısı olduğu ortaya konulmuştur. Ayrıca, bu araştırmacılar aidiyetin okul stres yaşantılarının etkilerinin öğrencinin akademik yaşantıları üzerindeki olumsuz etkisini azalttığını ve olumlu yaşantıları arttırdığını ifade etmişlerdir. Özetle, okul aidiyetinin öğrencinin okul işlevlerini artırmakla kalmayıp psikopatolojiye dönüşecek problemli davranışları ve durumları önlemeyle ilişkili olduğu da ifade edilmiştir.

Okul aidiyetinin öğrencilerin okul işlevleri üzerindeki etkisinin yanı sıra, yapılan çalışmalar aidiyet düzeyi yüksek olan bireylerin daha az uyum sorunları sergilediklerini göstermiştir (Altınsoy ve Özyer, 2018; Arslan ve Renshaw, 2018a; Booker 2006; Osterman, 2000; Pittman ve Richmond 2007). Bu çalışmada psikolojik uyum kavramı dışsallaştırılmış ve içselleştirilmiş davranış problemlerini içerecek şekilde ele alınmıştır. Yüksek düzeyde okul aidiyetinin yüksek benlik saygısı (Duru, 2015; Hernández, Robins, Widaman ve Conger, 2017), düşük şiddet eğilimi (Balkıs, Duru ve Buluş, 2005), düşük içselleştirilmiş problem ve dışsallaştırılmış davranışlar ile ilişkili olduğu bulunmuştur (Arslan, 2018a; Anderman, 2003; Bond ve diğerleri, 2007). Newman, Lohman ve Newman (2007) ergenlerde okul aidiyeti ile davranış problemleri arasındaki ilişkiyi incelemiş ve okul aidiyeti arttıkça ergenlerde içselleştirilmiş ve dışsallaştırılmış davranış problemlerinin azaldığını iletmiş̧tir. Benzer bir çalışmada, Cruwys ve diğerleri (2013) bireyin kendisini bir grubun anlamlı ve değerli bir parçası olarak görmesi hem psikolojik problemler üzerinde hem de ruhsal problemlerin gelişiminde önemli bir koruyucu faktör olarak işlev gördüğünü bulmuşlardır. Newman, Newman, Griffen, O'Connor ve Spas (2007) okul aidiyeti arttıkça depresif belirtilerin azaldığını bulmuş ve ortaokuldan liseye geçişte öğrencilerde okul aidiyetinin azalmasıyla birlikte depresyonda önemli bir artışın yaşandığını belirtmişlerdir. Duru ve Arslan (2014) evden kaçan kız ergenler üzerinde yaptıkları bir çalışmada, evden kaçma davranışı ile okul ve aile aidiyet yoksunluğunun ilişkili olduğunu bulmuştur. Dolayısıyla öğrencilerin okul aidiyet duygularının yüksek olması gelişimsel süreçte karşılaştıkları psikolojik problemler üzerinde koruyucu rol oynadığı ve bu öğrencilerin davranış problemlerini önleyebildiği şeklinde değerlendirilmektedir (Bond ve diğerleri, 2007; Lester, Waters ve Cross, 2013). Diğer taraftan öğrencinin kendisini okulda dışlanmış veya kabul edilmemiş olarak algılaması, daha fazla duygusal ve davranışsal sorunlar yaşamalarına neden olmaktadır (Arslan, 2018a).

İlgili alanyazın ışığında ve elde edilen araştırma sonuçları dikkate alındığında, ergenlik döneminde okul aidiyet duygusunun öğrencilerin okul işlevleri ve psikolojik uyum düzeyleri üzerinde etkili bir faktör olduğu söylenebilir. Birçok araştırmacı okul aidiyet duygusunun bireyin akademik, duygusal, sosyal ve davranışsal yaşantıları üzerinde önemli bir faktör olduğunu belirtmiştir (Arslan ve Duru, 2017; Baumeister ve Leary, 1995; Booker, 2006; Cruwys ve diğerleri, 2013; Osterman, 2000; Pittman ve Richmond, 2007; Tian, Zhang, Huebner, Zheng ve Liu, 2016). Son yıllarda Türkiye'de okul aidiyetine ilişkin yapılan çalışmalarda (Örn., Altınsoy ve Eryılmaz, 2017; Arslan ve Duru, 2017; Doğan ve Özdemir, 2019; Sarı, 2013) önemli bir artış yaşanmasına rağmen, özellikle hem bireysel hem de bağlamsal faktörleri kapsayacak şekilde çalışmaların sınırlı olduğu 
görülmektedir. Tüm bunlara ek olarak, ergenlik döneminde bireyin kimlik gelişiminde aile ve arkadaş ilişkilerinin etkisi dikkate alındığında (Arslan ve Duru, 2017; Yıldırım, 1997) aidiyet duygusunun ergenin sağlıklı bir kimlik gelişimi ile de yakından ilişkili olduğu söylenebilir (Ragelienè, 2016). Sonuç olarak, ilgili alanyazın ve kuramsal yapılar çerçevesinde, bu çalışmadaki temel araştırma soruları (a) okul aidiyetinin okul işlevleri ve psikolojik uyumun anlamlı bir yordayıcısı olup olmadı ğını ve (b) okul aidiyetinin okul işlevleri ve psikolojik uyumun ne kadarını açıkladığını incelemektir.

\section{Yöntem}

\section{Çalışma Grubu}

Ortaokul ve lise öğrencilerinin okul aidiyet duygusunun okul işlevleri ve psikolojik uyum ile olan ilişkisinin incelendiği bu çalışma, ilişkisel tarama modeline dayalı kesitsel bir çalışma olarak tasarlanmıştır. Araştırmanın örneklemini yaşları 11 ile 18 arasında değişen 333 ergen öğrenci oluşturmaktadır. Katılımcıların \%55.9'u (186) kız ve \%44.1'i (147) erkek öğrencidir ve yaş ortalamaları 15.45'tir (ss=1.75). Katılımcıların \%25.5'i ortaokul ve \%74.5'i lise öğrencisidir. Öğrencilerin \%17.6'sı ailesinin ekonomik düzeyini düşük, \%31.2'si orta ve \%51.2'si yüksek olarak belirtmiştir. Öğrencilere araştırma konusu ve ölçme araçları hakkında bilgi verildikten sonra uygulama sürecine geçilmiştir. Veri toplama araçları tek bir ölçme aracı haline getirilmiş ve araştırmaya gönüllü olarak katılmayı kabul eden öğrencilere dağıtılmıştır. Veri toplama süreci yaklaşık 40 dakika sürmüştür. Eksik veya hatalı veri, kayıp ve uç değerler nedeniyle 24 öğrenciye ait veri, analizlerden çıkartılmıştır. Veri toplama araçları katılımcılar tarafından ders saati içerisinde doldurulmuştur.

\section{Veri Toplama Araçları}

Bu çalışmada ilgili alanyazın ve kuramsal yapılardan hareketle, bireysel ve bağlamsal değişkenleri ölçmek amacıyla birden çok farklı ölçme araçlarından yararlanılmıştır. Araştırma kapsamında kullanılan ölçme araçlarının geçerlik ve güvenirlik sonuçlarına ilişkin bilgiler aşağıda verilmiştir.

Okul Aidiyeti. Arslan ve Duru (2017) tarafından Türkiye'de ortaokul ve lise öğrencilerinde aidiyet duygusunu ölçmek amacıyla geliştirilen Okul Aidiyet Ölçeği (OAÖ), öğrencilerin okul aidiyetini değerlendirmek amacıyla kullanılmıştır. Ölçek 10 madde ve okuldan dışlanma ile okulda kabul edilme olmak üzere iki alt ölçekten oluşan bir öz-bildirim veri toplama aracıdır (Kendimi bu okulun bir parçası olarak görüyorum., Kendimi bu okula ait hissetmiyorum.). Tüm maddeler (1) neredeyse hiçbir zaman ile (4) neredeyse her zaman arasında değişen dörtlü likert yapı kullanılarak puanlanmaktadır. Ölçek alt ölçekler şeklinde kullanılabileceği gibi olumsuz maddeler tersten puanlandıktan sonra toplam puan üzerinden de okul aidiyetini ölçmektedir. Ölçeğin psikometrik özelliklerinin incelendiği çalışma, ölçeğin güçlü iç tutarlık ve uyum değerlerine sahip olduğunu göstermiştir $\left(\chi^{2}=65.389, d f=34, p=.001\right.$; SRMR $=.046$, RMSEA [90 \% CI] = .065 [.038-.082], CFI = .97, TLI = .96). Benzer şekilde bu çalışmada da ölçeğin güçlü iç tutarlık değerine sahip olduğu bulunmuştur (Bkz. Tablo 1).

Psikolojik Uyum Problemleri. Öğrencilerin okuldaki psikolojik uyumunu değerlendirmek için Arslan (2018b; 2018c) tarafından geliştirilen Genç Dışsallaştırılmış Davranışlar Ölçeği (GDDÖ) ve Genç İçselleştirilmiş Davranışlar Ölçeği (GIDÖ) kullanılmıştır. Her iki ölçekte Türkiye'deki çocuk ve ergenlerde duygusal ve davranışsal sorunları ölçmek amacıyla geliştirilmiştir. GDDÖ 12 maddeden oluşan (Sık sık arkadaşlarımla kavga ederim., Dikkatimi yaptığım işe vermekte zorlanırım.) ve davranım bozuklukları, dikkat eksikliği ile hiperaktivite olmak üzere üç alt ölçekten meydana gelen dörtlü likert yapıda (1= neredeyse hiçbir zaman ile $4=$ neredeyse her zaman) öz-bildirim tarzı bir ölçme aracıdır. Ölçeğe ilişkin geçerlik ve güvenilirliğin incelendiği araştırmada, ölçeğin iyi uyum değerleri ürettiği $\left(\chi^{2}=95.54, d f=51, p<.001\right.$, CFI = .96, TLI = .97, RMSEA $(95 \%$ CI $)=.060(.041$, .079) ve güçlü iç tutarlık ( $\alpha=.79-.83)$ değerine sahip olduğu görülmüştür (Arslan, 2018b). Diğer bir ölçme aracı olan GIDÖ 10 maddelik (Kendimi rahatlatma ve sakinleştirmede zorlanırım., Kendimi üzgün ve karamsar hissediyorum.), iki alt ölçekten oluşan ve dörtlü likert yapıda ( $1=$ neredeyse hiçbir zaman ile $4=$ neredeyse her zaman $)$ öz-bildirim tarzı bir ölçme aracıdır. Araştırma sonuçları ölçeğin iyi uyum değerlerine $\left(\chi^{2}=59.38, d f=34, p<\right.$ $.05, \mathrm{CFI}=.97, \mathrm{TLI}=.95$, RMSEA $[95 \% \mathrm{CI}]=.061[.034, .086])$ ve güçlü bir iç tutarlığa $(\alpha=.85-.90)$ sahip olduğunu göstermiştir (Arslan, 2019b). Her iki ölçme aracı için bu çalışmada elde edilen bulgular, iyi düzeyde iç tutarlık 
değerlerine sahip olduklarını göstermiştir (Bkz. Tablo 1).

Okul İşlevleri. Çalışmanın kuramsal altyapısını oluşturan kuramlar perspektifinden okul işlevlerini bireysel ve toplumsal düzey ve bağlamlarda ölçebilmek için farklı ölçme araçları kullanılmıştır. Buradan hareketle katılımcıların okul işlevlerini toplumsal düzeyde değerlendirmek amacıyla Öğrenci Prososyallik Ölçeği (ÖPÖ), bireysel/intrapsişik düzeyde işlevlerini gözlemlemek için Öğrenci Öznel İyi Oluş Ölçeği (ÖÖIÖ), yine bireyse/içsel düzeyde akademik doyumu ölçmek için Akademik doyum Ölçeği (ADÖ) ve son olarak okul yaşantılarına ilişkin önemli bir gösterge olarak kabul edilen öğrencilerin akademik başarıları (aldıkları son karne notu) kullanılmıştır. Böylece okul işlevlerinden hem içsel/bireysel hem de toplumsal/bağlamsal boyutlar ele alınmış ve çok daha kapsayıcı ve bütüncül bir bakış açısı sağlanmaya çalışılmıştır.

Öğrencilerin prososyal davranışları Öğrenci Prososyallik Ölçeği (ÖPÖ) aracıllğıyla değerlendirilmiştir. Ölçek dört maddeden oluşmakta (Bu okuldaki insanlar için iyi şeyler yaparım.) ve dörtlü likert yapı (1= neredeyse hiçbir zaman ile $4=$ neredeyse her zaman) kullanılarak derecelendirilmektedir (Renshaw, 2014). Bu araştırma kapsamında ölçeğin uyarlama çalışması yapılmış ve bu örneklem üzerinde psikometrik özellikleri incelenmiştir. Ölçek ilk olarak Türkçe ve İngilizce diline hakim üç uzman tarafından Türkçe'ye çevrilmiştir. Daha sonra İngilizce'ye geri çeviri yapılarak ölçeğin aslı ile karşılaştırması yapılmıştır. Çeviri çalışması sonrasında doğrulayıcı faktör analizi ile bu örneklem üzerinde faktör yapısı test edilmiştir. Birinci ve üçüncü maddeler arasında modifikasyon yapıldıktan sonra, analiz sonuçları ölçeğin iyi düzeyde uyum değeri ürettiğini $\left(\chi^{2}=2.816, s d=1, \mathrm{p}=.093\right.$; RMSEA $\left.[90 \% \mathrm{CI}]=.074, \mathrm{CFI}=.99, \mathrm{TLI}=.99\right)$ ve güçlü iç tutarlık $(\alpha=.79)$ ve gizil değişken güvenirlik (latent construct reliability) katsayısına $(H=.81)$ sahip olduğunu göstermiştir. Ölçeğin faktör yük değeri .63 ile .82 arasında değişmektedir. Bu sonuçlar ölçeğin ergenlerde prososyal davranışları ölçmede geçerli ve güvenilir bir ölçme aracı olduğunu göstermektedir.

Öğrencilerin okulda pozitif işlevlerini ölçmek amacıyla Öğrenci Öznel İyi Oluş Ölçeği (ÖÖIÖ) kullanılmıştır. Ölçek 16 maddelik dörtlü likert tarzı bir öz bildirim ölçeğidir (Başarılı bir öğrenciyimdir., Okulda iyi işler yaparım., Okulda öğrenirken ve çalışırken mutlu olurum.) (Renshaw, Long ve Cook, 2015). Renshaw ve Arslan (2016) tarafından Türk ergenler için psikometrik özellikleri incelenmiş, ölçeğin iyi uyum değerine $\left(\chi^{2}\right.$ $=411.45, d f=98, p<.001, \mathrm{CFI}=.908, \mathrm{SRMR}=.054, \mathrm{RMESA}[90 \% \mathrm{CI}]=.078[.071, .086])$ ve güçlü iç tutarlık $(\alpha=$ .89) düzeyine sahip olduğu görülmüştür. Sosyal bağlllık ve aidiyet duygusu arasındaki güçlü ilişki dikkate alındığında, bu araştırmada ölçeğin okula bağlılık boyutu analizlere dahil edilmemiştir.

Ergenlerin okul işlevleri kapsamında akademik doyumları Akademik Doyum Ölçeği (ADÖ) aracılığıyla değerlendirilmiştir. Ölçek beş maddelik beşli likert yapıda bir ölçme aracıdır (Bir bütün olarak bu okuldan aldığım eğitimden memnunum.)( Schmitt, Oswald, Friede, Imus ve Merritt, 2008). Ölçeğin uyarlama çalışması Balkis (2013) tarafından geçerlik ve güvenirlik çalışması yapılmış, ölçeğin tek faktörlük yapısının varyansın \%63.70'ini açıkladığı ve güçlü iç tutarlık değerine $(\alpha=.86)$ sahip olduğu bulunmuştur. Son olarak, öğrencilerin akademik başarıları, son aldıkları karne notu ile değerlendirilmiştir. Bu amaçla öğrencilere son aldıkları karne notuna yönelik tek maddelik bir soru yöneltilmiş ve belirtmeleri istenmiştir. Bu araştırma kapsamında elde edilen bulgular, tüm ölçeklerin iyi düzeyde iç tutarlık değerlerine sahip olduklarını göstermiştir (Bkz. Tablo $1)$.

\section{Verilerin Analiz Edilmesi}

Verilere ilişkin kayıp ve uç değerler incelendikten sonra, değişkenlere ilişkin betimleyici istatistikler incelenmiştir. Kline (2005) göre basıklık değerinin 3.0 ve çarpıklık değerinin 10.0 değerinin altında olması normallik varsayımının sağlandığının önemli bir göstergesidir. Değişkenlere ilişkin normallik varsayımı basıklık ve çarpıklık değerleriyle incelenmiştir. Daha sonra Pearson korelasyon analizi aracılığı ile değişkenler arasındaki ilişki incelenmiştir. Son olarak, okul aidiyet duygusunun öğrencilerin okul işlevleri ve psikolojik iyi oluşları üzerindeki yordayıcı etkisi, yol analizi (path analysis) aracılı̆̆ ile test edilmiştir. Yol analizi yapısal eşitlik modeli kapsamında bağımsız değişkenin bir veya birden çok bağımlı değişken üzerinde yordayıcı etkisini görmeye olanak tanıyan bir analiz türüdür. Elde edilen etki büyüklüğü $\left(R^{2}\right)$, Cohen (1988) tarafından önerilen değerlendirme çerçevesinde yapılmıştır (<.06 = düşük, .06-.14 = orta, $\geq .14=$ büyük). Araştırma 
kapsamında yapılan tüm analizler, SPSS 25 ve AMOS 24 paket programlar aracılığıyla gerçekleştirilmiştir.

\section{Bulgular}

Okul aidiyetinin öğrencilerin okul işlevleri ve uyumu üzerindeki etkisini incelemeden önce, değişkenlere ilişkin betimleyici istatistikler incelenmiştir. $\mathrm{Bu}$ analizler kapsamında değişkenlere ilişkin normallik varsayımına ve iç tutarlık değerlerine de bakılmıştır. Daha sonra değişkenler arasındaki ilişkiyi incelemek amacıyla korelasyon analizi yapılmıştır. Değişkenlere ilişkin betimleyişi istatistikler Tablo 1'de verilmiştir.

Tablo I

Değişkenlere İlişkin Betimleyici İstatistikler

\begin{tabular}{lccccc}
\hline & Ort. & Ss & Basıklı & Çarplklık & $\alpha$ \\
\hline Okul aidiyet & 31.44 & 6.25 & -.40 & -.67 & .85 \\
Akademik başarı & 78.17 & 9.49 & -.17 & -.29 & - \\
Öğrenmeden zevk alma & 12.43 & 2.90 & -.67 & -.14 & .78 \\
Eğitimsel amaçlar & 13.25 & 2.78 & -.96 & .28 & .82 \\
Akademik yeterlik & 12.66 & 2.68 & -.54 & -.30 & .86 \\
Akademik doyum & 18.70 & 5.12 & -.74 & -.06 & .79 \\
Prososyal davranişlar & 13.90 & 2.56 & -1.55 & 2.08 & .84 \\
İçselleştirilmiş problemler & 19.60 & 4.81 & .69 & .45 & .76 \\
Dişsallaştırmış problemler & 20.95 & 7.03 & .57 & -.07 & .88 \\
\hline
\end{tabular}

Değişkenlere ilişkin betimleyici istatistikler, basıklık değerinin -1.52 ile .69 arasında, çarpıklık değerinin .67 ile 2.08 arasında değiştiğini göstermektedir. Bu sonuçlar, değişkenlerin analizler için gerekli olan normallik varsayımını karşıladıklarını göstermektedir (Kline, 2005). Ayrıca ölçeklere ilişkin iç tutarlık değerleri, tüm ölçeklerin kabul edilebilir ve güçlü arasında değişen iç tutarlık değerine $(\alpha=.76-.88)$ sahip olduklarını göstermektedir. Betimleyici istatistikler incelendikten sonra, değişkenler arasındaki ilişkiyi incelemek amaciyla Pearson korelasyon analizi yapılmıştır. Pearson korelasyon analizine ilişkin bulgular Tablo 2'de verilmiştir.

\section{Tablo II}

Değişkenler Arasındaki Korelasyon Sonuçları

\begin{tabular}{|c|c|c|c|c|c|c|c|c|c|}
\hline Değişkenler & $\mathrm{OA}$ & $\mathrm{AB}$ & ÖZA & EA & AY & İP & $\mathrm{DP}$ & $\mathrm{AD}$ & $\mathrm{PD}$ \\
\hline Okul aidiyet & 1 & & & & & & & & \\
\hline Akademik başarı & $.15^{*}$ & 1 & & & & & & & \\
\hline Öğrenmeden zevk alma & $.45^{* *}$ & .11 & 1 & & & & & & \\
\hline Eğitimsel amaçlar & $.44^{* *}$ & $.19^{* *}$ & $.67^{* *}$ & 1 & & & & & \\
\hline Akademik yeterlik & $.42^{* *}$ & $.39^{* *}$ & $.56^{* *}$ & $.57^{* *}$ & 1 & & & & \\
\hline İçselleştirilmiş problem. & $-.39^{* *}$ & $-.15^{*}$ & $-.29^{* *}$ & $-.33^{* *}$ & $-.27^{* *}$ & 1 & & & \\
\hline Dişsallaştırmış problem. & $-.43^{* *}$ & -.06 & $-.34^{* *}$ & $-.33^{* *}$ & $-.37^{* *}$ & $.57^{* *}$ & 1 & & \\
\hline Akademik doyum & $.34^{* *}$ & $.13^{*}$ & $.42^{* *}$ & $.44^{* *}$ & $.31^{* *}$ & $-.20^{* *}$ & $-.22^{* *}$ & 1 & \\
\hline Prososyal davranışlar & $.45^{* *}$ & $.24^{* *}$ & $.43^{* *}$ & $.44^{* *}$ & $.40^{* *}$ & $-.34^{* *}$ & $-.24^{* *}$ & $.42^{* *}$ & 1 \\
\hline
\end{tabular}
${ }^{*} p<.05,{ }^{* *} p<.001$

Korelasyon analiz sonuçları, okul aidiyeti ile akademik başarı $(r=.15, p<.05)$, öğrenmeden zevk alma ( $r=$ $.45, p<.001)$, eğitimsel amaçlar $(r=.44, p<.001)$, akademik yeterlik $(r=.42, p<.001)$, akademik doyum $(r=.34$, $p<.001)$ ve prososyal davranışlar $(r=.45, p<.001)$ arasında pozitif yönde ve anlamlı düzeyde ilişkili olduğu görülmüştür. Ayrıca okul aidiyetinin içselleştirilmiş $(r=-.39, p<.001)$ ve dışsallaştırılmış $(r=-.43, p<.001)$ problemler ile negatif yönde ve anlamlı bir ilişkiye sahip olduğu bulunmuştur. Bu sonuçlar, öğrencilerde okul aidiyeti artarken duygusal ve davranışsal problemlerin azaldığını ve okul işlevlerinde de anlamlı bir artışın olduğunu göstermektedir. Korelasyon sonuçları incelendikten sonra, okul aidiyetinin öğrencilerin okul işlevleri ve uyumu üzerindeki yordayıcı etkisini görmek amacıyla yol analizi yapılmıştır. Yol analizine ilişkin elde edilen bulgular Şekil 1'de verilmiştir. 


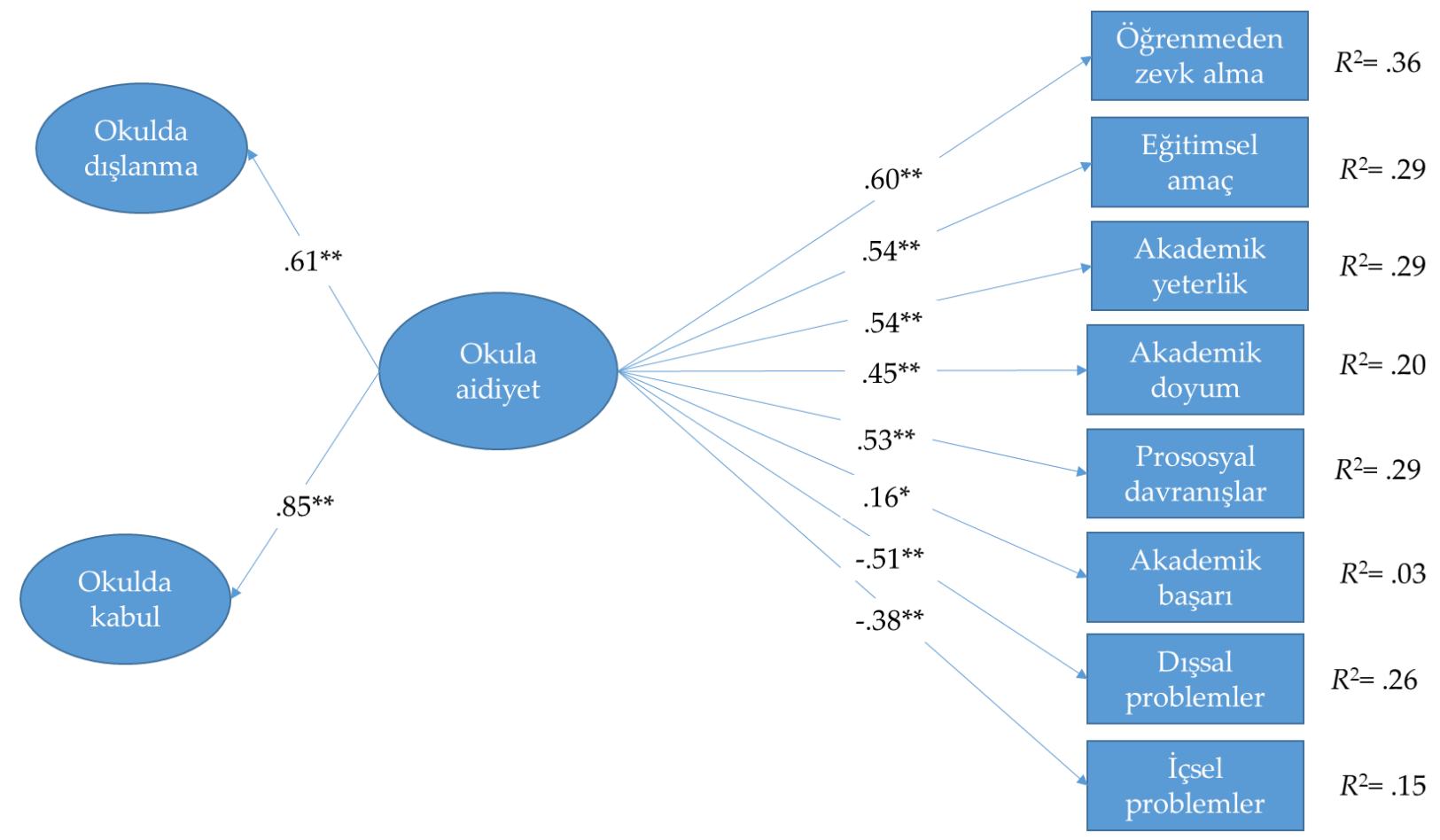

Şekil 1. Okul aidiyetinin öğrencilerin okul işlevleri ve psikolojik uyumu üzerindeki etkisine ilişkin yol analizi sonuçları ${ }^{*} p<.05,{ }^{* *} p<.001$.

Analiz sonuçları incelendiğinde, okul aidiyetinin tüm değişkenleri anlamlı düzeyde yordadığı görülmektedir. Okul aidiyetinin öğrencilerin akademik başarı $(\beta=.16, p<.05)$, öğrenmeden zevk alma $(\beta=.60$, $p<.001)$, eğitimsel amaçlar $(\beta=.54, p<.001)$, akademik yeterlik $(\beta=.54, p<.001)$, akademik doyum $(\beta=.45, p<.001)$ ve prososyal davranımlarını ( $\beta=.53, p<.001)$ pozitif yönde ve anlamlı ve orta düzeyde yordadığı görülmüştür. Diğer yandan okul aidiyetinin öğrencilerin içselleştirilmiş $(\beta=-.38, p<.001)$ ve dışsallaştırılmış $(\beta=-.51, p<.001)$ problemlerini negatif yönde ve anlamlı ve orta düzeyde yordadığı bulunmuştur. Etki büyüklükleri açısından bakıldığında, akademik başarı $\left(R^{2}=.03\right)$ dışındaki diğer tüm değişkenler üzerinde okul aidiyetinin güçlü bir etkisinin ( $R^{2}=.15$ ile .36 arasında) olduğu görülmektedir. Okul aidiyetinin okul işlevlerinden öğrenmeden zevk almanın güçlü bir yordayıcısı olduğu bulunmuştur. Psikolojik uyuma ilişkin sonuçlara bakıldığında ise okul aidiyetinin içselleştirmiş problemlere göre dışsallaştırılmış problemlerin daha güçlü bir yordayıcısı olduğu görülmüştür. Elde edilen bu bulgular, okul aidiyetinin öğrencilerin okul işlevleri ve uyumları üzerinde etkili bir faktör olduğunu göstermektedir.

\section{Sonuç ve Tartışma}

Okul ergenin yaşamında merkezi bir konumdadır. Okula yönelik ergenin daha olumlu duygular içerisinde olması ve kendisini okulun bir parçası olarak görmesi, onun hem eğitimsel hem gelişimsel işlevleri üzerinde önemli bir yer edinmektedir (Arslan, 2016; Korpershoek ve diğerleri, 2019). Bu çalışmada ergenlerde okul aidiyet duygusunun okul işlevleri ve psikolojik uyum üzerindeki etkisi incelenmiştir. Korelasyon analiz sonuçları, ergenlerde okul aidiyeti artarken içselleştirilmiş ve dışsallaştırılmış problemlerin azaldığını ve okul işlevlerinde de anlamlı bir artışın olduğunu göstermektedir. Yol analiz sonuçları, okul aidiyetinin tüm değişkenlerini anlamlı düzeyde yordadığını göstermiştir. Okul aidiyetinin öğrencilerin akademik başarı, öğrenmeden zevk alma, eğitimsel amaçlar, akademik yeterlik, akademik doyum ve prososyal davranımlarını pozitif yönde ve anlamlı düzeyde yordadığı görülmüştür. Diğer yandan okul aidiyetinin ergenlerde içselleştirilmiş ve dışsallaştırılmış problemleri negatif yönde ve anlamlı düzeyde yordadığı bulunmuştur. Akademik başarı dışındaki diğer tüm değişkenler üzerinde okul aidiyetinin güçlü bir etkisinin olduğu görülmektedir.

Bu çalışmada elde edilen bulgular, okul aidiyetine ilişkin alanyazınla ve yapılan çalışmalar ile uyuşmakta, 
ergenlerde aidiyet duygusu arttıkça öğrenmeden zevk alma, eğitimsel amaçlar, akademik yeterlik, akademik doyum, prososyal davranışlar ve akademik başarının arttığını göstermektedir. Aidiyet duygusu bireyin gelişim sürecinde (Baumeister ve Leary, 1995) ve okul yaşantısında (Arslan ve Duru, 2017; Kim ve diğerleri, 2019) temel bir motivasyon kaynağı olarak tanımlanmaktadır. Psikolojide bireyin içsel süreçlerini merkeze alan ve son yıllarda daha fazla araştırmaya konu olan öz-belirleme kuramına göre bireyin psikolojik açıdan sağlıklı ve üretken olup motivasyonun yüksek olması için en önemli koşullardan birisi de aidiyettir (Çankaya, 2016; Deci ve Ryan, 2000). Benzer şekilde kabul ve kararlılık terapisi de aidiyetin kuramsal bir yere sahip olduğunu göstermiştir (Hayes ve diğerleri, 2012; Tanhan, 2019). Bireyin okul ortamında kabul görmesi ve değerli olduğunu hissetmesi veya bireye saygı duyulması, olumlu yaşantıları arttırırken okuldan dışlanması, reddedilmesi veya kendini değersiz olarak görmesi birçok gelişimsel probleme neden olabilmektedir (Joyce ve Early, 2014; Osterman, 2000; Pate, Maras, Whitney ve Bradshaw, 2017). Örneğin, okul ortamında dışlanmışlık yaşayan ergenlerin daha fazla duygusal ve davranışsal problemler yaşadıkları ve daha düşük iyi oluş düzeyine sahip oldukları belirtilmektedir (Arslan, 2018a). Bu çalışmadan elde edilen sonuçlar ile yapılan çalışmalarda paralel olarak okul aidiyet düzeyi yüksek olan öğrencilerin akademik başarı (Arslan, 2016; Booker, 2004; Goodenow ve Grady, 1993; Sarı, 2013), eğitimsel ve akademik amaçlar, akademik öz-yeterlik (Anderman, 2003; Arslan, 2016) ve akademik motivasyon (Gillen-O'Neel ve Fuligni, 2013) düzeylerinin daha yüksek olduğu rapor edilmiştir. Goodenow (1993) yaptı̆̆ çalışmada, okulda aidiyet duygusu arttıkça öğrencilerin motivasyon düzeylerinin arttığı ve akademik başarılarının yükseldiğini bulmuştur. Diğer bir çalışmada ise Faircloth ve Hamm (2005) dört farklı etnik grupta okul aidiyetinin etkisini incelemiştir. Araştırmadan elde edilen bulgular, bir grup dışındaki tüm etnik gruplarda okul aidiyetinin öğrencilerin okula değer verme, yeterlik inançları ve akademik başarıları üzerinde etkili bir faktör olduğunu göstermiştir. Roeser, Midgley ve Urdan (1996) tarafından yapılan çalışmada okul aidiyeti arttıkça akademik öz-yeterlik, okula yönelik olumlu duygular, öz-farkındalık ve akademik başarıda da anlamlı bir artışın olduğu bulunmuştur. Boylamsal araştırma sonuçları da okul aidiyet duygusunun öğrencinin eğitimsel işlevleri üzerinde önemli bir faktör olduğunu desteklemektedir (Gillen-O'Neel ve Fuligni, 2013). Ayrıca yapılan bazı çalışmalar okul aidiyet duygusunun stres durumları karşısında bireyin okul işlevleri üzerinde koruyucu etkiye sahip olabileceğini ortaya koymuştur (Mcmahon ve diğerleri, 2008). Sonuç olarak bu çalışmadan elde edilen bulgular ilgili kuramsal yapılar ve alanyazın ile tutarlı olarak, okul aidiyetinin ergenlerin okul işlevleri üzerinde önemli bir faktör olduğunu göstermiştir. Bu bulgular, bu konuda yapılacak araştırma ve uygulamalara 1şık tutacak niteliktedir.

Okul aidiyet duygusu ve psikolojik uyum problemleri arasındaki ilişki incelendiğinde, yüksek düzeyde aidiyet duygusuna sahip ergenlerin daha az içselleştirilmiş ve dışsallaştırılmış problemler sergiledikleri bulunmuştur. Özellikle okul aidiyetinin öğrencilerin dışsallaştırılmış davranış problemlerinin önemli bir yordayıcısı olduğu görülmüştür. Bireyin kendisini bir grubun anlamlı ve değerli bir parçası olarak görmesi, bireyin psikolojik uyumu üzerinde önemli bir koruyucu faktör olarak işlev görmektedir (Cruwys ve diğerleri, 2013; Kim ve diğerleri, 2019). Dolayısıyla okul ortamında kendisini değerli görmeyen, kabul edilmeyen ve dışlanmışlık yaşayan ergenlerin akranlarına göre daha fazla psikolojik uyum sorunları yaşadıkları ve iyi oluş düzeyini daha düşük olduğu söylenebilir (Arslan, 2018a). Bu sonuçlar ile tutarlı olarak yapılan çalışmalar, aidiyet düzeyi yüksek olan bireylerin daha az uyum sorunları yaşadıklarını ortaya koymuştur (Altınsoy ve Özyer, 2018; Booker 2006; Osterman, 2000; Pittman ve Richmond 2007). Yüksek düzeyde okula aidiyet duygusunun düşük şiddet eğilimi (Balkıs ve diğerleri, 2005), düşük duygusal ve davranışsal problemlerle ile ilişkili olduğu bulunmuştur (Anderman, 2003; Arslan, 2018c; Arslan ve Renshaw, 2018b; Bond ve diğerleri, 2007). Örneğin, Newman, Lohman ve diğerleri (2007) ergenlerde okul aidiyeti ile davranış problemleri arasındaki ilişkiyi incelemiş ve okul aidiyeti artıkça ergenlerde içselleştirilmiş ve dışsallaştırılmış davranış problemlerinin azaldığını rapor etmişlerdir. Diğer bir çalışmada ise eğitim kademleri arasındaki geçişlerde okul aidiyetinin azalması nedeniyle ergenlerde daha fazla depresif belirtilerinin gözlendiği belirtilmiştir (Newman, Newman ve diğerleri, 2007). Aidiyet duygusu zayıf veya düşük olan ergenlerin daha fazla riskli davranışlar sergiledikleri görülmüştür (Duru ve Arslan, 2014). Pittman ve Richmond (2007) yüksek aidiyet duygusu olan bireylerin daha az duygusal ve davranışsal problem sergiledikleri, akademik olarak daha başarılı oldukları, daha yüksek yeterlik algısına sahip oldukları ve kendilerine ilişkin daha olumlu bir algıya 
sahip olduklarını belirtmiştir. Ayrıca okul aidiyet duygularının yüksek olması, sadece şu anki psikolojik uyum üzerinde değil aynı zamanda sonraki ruhsal problemler üzerinde koruyucu rol üstlenmekte ve aidiyet duygusu yüksek olan kişilerin daha az duygusal ve davranışsal problemler sergiledikleri görülmektedir (Bond ve diğerleri, 2007; Lester ve diğerleri, 2013). Dolayısıyla okul aidiyet duygusunun bireylerin psikolojik uyumu ve sağlıklı gelişimleri üzerinde önemli rol oynadığı söylenebilir.

Son yıllarda okul aidiyetine yönelik yapılan çalışmalarda önemli bir artış yaşansa da, okulda aidiyet duygusunun bireyin okul yaşantıları ve psikolojik uyumu üzerindeki etkisine ilişkin çalışmaların sınırlı olduğu görülmektedir. Özellikle Türkiye'de okul aidiyetine ilişkin sınırlı sayıda çalışmanın olması, yapılacak çalışmaların önemini daha da arttırmaktadır Bu açıdan bu çalışmanın alanyazında önemli bir boşluğu doldurduğu düşünülmektedir. Bu araştırma sonuçları, okul aidiyet düzeyi yüksek olan öğrencilerin akademik olarak daha başarıll, öğrenmeden daha fazla zevk ve doyum alan, akademik öz-yeterlik düzeyi yüksek ve daha fazla prososyal davranışlar sergileyen bireyler olduğunu göstermiştir. Diğer bir ifade ile ergenlerde okula aidiyet arttıkça okul işlevlerinde de artışın olduğu bulunmuştur.

Bu sonuçlara dayalı olarak okul aidiyetinin okul psikolojik danışmanları ve okul yöneticileri tarafından desteklenmesinin öğrencilerin öğrenme yaşantılarına önemli katkı sağlayacağı söylenebilir. Okul psikolojik danışmanları tarafından akademik başarısızlık, okula devamsızlık gibi olumsuz yaşantılara sahip öğrencilere yönelik yapılacak müdahale çalışmalarında okul aidiyetinin göz önünde bulundurulması yararlı olacaktır. Ayrıca öğrencilerin okul aidiyet duygusunu desteklemek amacıyla, daha olumlu bir okul ikliminin oluşturulması hem aidiyet duygusuna olumlu yansıyacak hem de öğrencilerin eğitimsel işlevleri ve psikolojik uyumları üzerinde etkili olacaktır (Erdoğdu ve Yüzbaş, 2018; Sarı ve Özgök, 2014; Tanhan, 2018; Tanhan ve Francisco, 2019). Bunlara ek olarak ruh sağllğı alanındaki bazı araştırmacılar Türkiye'de ruh sağlığı hizmetlerinde yarı-deneysel ve deneysel çalışmaların çok az olduğunu bundan dolayı da ruh sağlığı alanında yarı-deneysel çalışmalar yapılması gerektiğini vurgulamışlardır (Buluş ve Şahin, 2019; Tanhan, 2018). Bundan dolayı pozitif psikoloji ve psikopatoloji temelli hazırlanacak ruhsal eğitim ve hizmetlerin kapsamlı ve bütüncül benzer deneysel çalışmalar okul aidiyeti için de yapılabilir.

Araştırma sonuçları, ergenlerde görülen içselleştirilmiş ve dışsallaştırılmış problemler üzerinde aidiyet duygusunun etkili bir faktör olduğunu göstermiştir. Ergenlerde okul aidiyet duygusu arttıkça psikolojik uyum problemlerinin azaldığı görülmektedir. Bireyin psikososyal gelişiminde okul yaşantılarının önemi dikkate alındığında, ruh sağlığı hizmeti sunanların duygusal ve davranışsal problemleri olan öğrencilerle çalışırken aidiyet duygusunun etkisini göz önünde bundurmaları yararlı olacaktır. Düzenlenecek önleyici ve müdahale edici çalışmalarda aidiyet duygusunu destekleyici yaşantılara yer verilmesi hem ergenin gelişimine olumlu yansıyacak hem de uyum problemlerinin azaltılmasında önemli rol oynayacaktır. Psiko-eğitim programları aracılığıyla öğrencilerin olumlu okul yaşantıları arttırılarak aidiyet duyguları desteklenebilir. Okul psikolojik danışmanları tarafından duygusal ve davranışsal sorunlar yaşayan öğrencilerle yapılan bireyle psikolojik danışma sürecinde, okul aidiyetinin etkisi dikkate alınarak verilen hizmetlerin destekleyici yaşantıları içerecek şekilde sunulmasının yararlı olacağı düşünülmektedir. Bununla birlikte aidiyet duygusu düşük veya dışlanmışlık yaşayan bireylerin daha fazla uyum problemleri yaşadıkları göz önüne alındığında (Arslan, 2018c; Baumeister ve Leary, 1995) ergenlere yönelik sunulacak ruh sağlığı hizmetlerinde aidiyet duygusunun önemi daha da artmaktadır.

Bu araştırma sonuçlarının bir takım sınırlılıklar çerçevesinde değerlendirilmesi yararlı olacaktır. Öncelikle bu araştırma Türkiye'nin batı bölgesinde bulunan bir ildeki iki devlet okulunda öğrenim gören öğrenciler ile gerçekleştirilmiştir. Dolayısıyla bu araştırmanın sonuçları bütün ortaokul ve lise öğrencisi ergenler için genellenemez. Yapılacak yeni çalışmaların, Türkiye'nin farklı bölgelerini kapsayacak şekilde daha büyük örneklemlerle yapılması yararlı olacaktır. Ayrıca bu çalışmada veriler öz-bildirime dayalı veri toplama araçları ile elde edilmiştir. Farklı ölçme yöntemlerinin kullanılarak yeni araştırmaların yapılması büyük önem taşımaktadır. Bu araştırmanın ilişkisel tarama modeline dayalı kesitsel bir çalışma olması, elde edilen bulguların neden-sonuç ilişkisi çerçevesinde değerlendirilmesini güçleştirmektedir. Bu nedenle okul aidiyetin okul işlevleri ve psikolojik uyum üzerindeki etkisini görmek amaciyla boylamsal, yarı-deneysel ve deneysel araştırmaların yapılması alanyazında önemli boşlukları dolduracaktır. Son olarak, bu araştırmada aidiyet 
duygusunun okul yaşantıları üzerindeki etkisine bakılmıştır ve aidiyet duygusunun temel gereksinimlerden biri olduğu dikkate alındığında, ileriki çalışmalarda ergenlerde okul aidiyetinin farklı psikososyal değişkenler üzerindeki etkisinin incelenmesi de araştırma ve uygulamalar için yararlı olabilir.

\section{Kaynaklar}

Adelabu, D. H. (2007). Time perspective and school membership as correlates to academic achievement among African American adolescents. Adolescence, 42(167), 525-538.

Altınsoy, F. ve ve Eryllmaz, A. (2017). School belonging in adolescence: Relationships with life goals and attachment patterns. International Online Journal of Educational Sciences, 9(4), 1038-1051.

Altınsoy, F. ve Özyer, K. K. (2018). Liseli ergenlerde okula aidiyet duygusu: Umutsuzluk ve yalnızlık ile ilişkileri. Ilköğretim Online, 17(3), 1751-1764

Anderman, L. H. (2003). Academic and social perceptions as predictors of change in middle school students' sense of school belonging. Journal of Experimental Education, 72(1), 5-22.

Arslan, G. (2016). Relationship between sense of rejection, academic achievement, academic efficacy, and educational purpose in high school students. Education \& Science, 41(183), 293-304.

Arslan, G. (2018a). School-based social exclusion, affective wellbeing, and mental health problems in adolescents: A Study of mediator and moderator role of academic self-regulation. Child Indicator Research. 11(3), 963-980. doi:10.1007/s12187-017-9486-3

Arslan, G. (2018b). Development and validation of the Youth Externalizing Behavior Screener: A brief and effective measure of behavioral problems. International Journal of School E Educational Psychology. Advance online publication. doi:10.1080/21683603.2018.1466747

Arslan, G. (2018c). Exploring the association between school belonging and emotional health among adolescents. International Journal of Educational Psychology, 7(1), 11-21. doi:10.17583/ijep.2018.3117

Arslan G. (2019a). Positive psychological traits, school functioning, and psychological adjustment in elementary schoolchildren. Journal of Psychologists and Counsellors in Schools. Advance online publication. doi: 10.1017/jgc.2018.24

Arslan, G. (2019b). Measuring emotional problems in Turkish adolescents: Development and initial validation of the youth internalizing behavior screener. Manuscript submitted for publication.

Arslan, G. ve Duru, E. (2017). Initial development and validation of the School Belongingness Scale. Child Indicators Research, 10(4), 1043-1058.

Arslan, G. ve Renshaw, T. L. (2018a). Psychometrics of the youth internalizing problems screener with Turkish adolescents. International Journal of School \& Educational Psychology. Advance online publication, doi:10.1080/21683603.2018.1459990

Arslan, G. ve Renshaw, T. L. (2018b). Student subjective wellbeing as a predictor of adolescent problem behaviors: A Comparison of first-order and second-order factor effects. Child Indicators Research, 11(2), 507-521. doi: 10.1007/s12187-017-9444-0

Babakhani, N. (2014). Perception of class and sense of school belonging and self-regulated learning: A causal model. Procedia-Social and Behavioral Sciences, 116, 1477-1482. doi:10.1016/j.sbspro.2014.01.420

Balkis, M. (2013). Academic procrastination, academic life satisfaction and academic achievement: The mediation role of rational beliefs about studying. Journal of Cognitive \& Behavioral Psychotherapies, 13(1), 57-74.

Balkis, M., Duru, E. ve Buluş, M. (2005). Şiddete yönelik tutumların özyeterlik, medya, şiddete yönelik inanç, arkadaş grubu ve okula bağlılık duygusuyla ilişkisi. Ege Eğitim Dergisi, 6(2), 79-96. 
Baumeister, R. ve Leary, M. R. (1995). The need to belong: Desire for interpersonal attachments as a fundamental human motivation. Psychological Bulletin, 117(3), 497-529.

Bond, L., Butler, H., Thomas, L., Carlin, J., Glover, S., Bowes, G. ve Patton, G. (2007). Social and school connectedness in early secondary school as predictors of late teenage substance use, mental health, and academic outcomes. Journal of Adolescent Health, 40(4), 357-e9-357-e18.

Booker, K. C. (2004). Exploring school belonging and academic achievement in African American adolescents. Curriculum and Teaching Dialogue, 6(2), 131-143.

Booker, K. C. (2006). School belonging and the African American adolescent: What do we know and where should we go? The High School Journal, 89(4), 1-7.

Bronfenbrenner, U. (1977). Toward an experimental ecology of human development. American Psychologist, 32(7), 513-531.

Buluş, M. ve Şahin, S. G. (2019). Estimation and standardization of variance parameters for planning clusterrandomized trials: A short guide for researchers. Ĕ̆itimde ve Psikolojide Ölçme ve Değerlendirme Dergisi, 10(2), 179-201.

Cohen, J. (1988). Statistical power analysis for the behavioral sciences. Hillsdale: Lawrence Earlbaum Associates.

Cruwys, T., Dingle, G. A., Haslam, C., Haslam, S. A., Jetten, J. ve Morton, T. A. (2013). Social group memberships protect against future depression, alleviate depression symptoms and prevent depression relapse. Social Science \& Medicine, 98(2013), 179-186.

Çankaya, Z. C. (2016). Özerklik desteği, temel psikolojik ihtiyaçların doyumu ve öznel iyi olma: Öz-belirleme kuramı. Türk Psikolojik Danışma ve Rehberlik Dergisi, 4(31), 23-31.

Deci, E. L. ve Ryan, R. M. (1991). Self-determination theory and the facilitation of intrinsic motivation, social development, and well-being. American Psychologist, 55(1), 68-78.

Deci, E. L. ve Ryan, R. M. (2000). The "what" and "why" of goal pursuits: Human needs and the selfdetermination of behavior. Psychological inquiry, 11(4), 227-268.

Doğan, S. ve Özdemir, Ç. (2019). Sivas ilinde öğrenim gören yabancı uyruklu öğrencilerin okul iklimine etkisinin incelenmesi. Electronic Journal of Social Sciences, 18(69), 205-227.

Duru, E. (2015). Genel Aidiyet Ölçeğinin psikometrik özellikleri: Geçerlik ve güvenirlik çalışması. Türk Psikolojik Danışma ve Rehberlik Dergisi, 5(44), 125-135.

Duru, E. ve Arslan, G. (2014). Evlenmek amaciyla evden kaçan kız ergenler: Bir olgubilim çalışması. Türk Psikolojik Danışmanlık ve Rehberlik Dergisi, 41(5), 36-48.

Erdem, Ş. (2017). Attachment to parents and resilience among high school students. Journal of Positive Psychology and Wellbeing, 1(1), 22-33.

Erdoğdu, M. Y. ve Yüzbaş, D. (2018). Lise öğrencilerinin okula bağlllık ile genel öz-yeterlilik düzeyleri arasındaki ilişki. Journal of Suleyman Demirel University Institute of Social Sciences, 32(1), 205 - 227

Faircloth, B. S. ve Hamm, J. V. (2005). Sense of belonging among high school students representing 4 ethnic groups. Journal of Youth and Adolescence, 34(4), 293-309.

Gillen-O'Neel, C. ve Fuligni, A. (2013). A longitudinal study of school belonging and academic motivation across high school. Child Development, 84(2), 678-692.

Goodenow, C. (1993). The psychological sense of school membership among adolescents: Scale development and educational correlates. Psychology in the Schools, 30(1), 79-90.

Goodenow, C. ve Grady, K. E. (1993). The relationship of school belonging and friends' values to academic motivation among urban adolescent students. The Journal of Experimental Education, 62(1), 60-71. 
Hayes, S. C., Strosahl, K. D. ve Wilson, K. G., (2012). Acceptance and commitment therapy: The process and practice of mindful change (2. bs.). New York, NY: The Guilford Press

Hernández, M. M., Robins, R. W., Widaman, K. F. ve Conger, R. D. (2017). Ethnic pride, self-esteem, and school belonging: A reciprocal analysis over time. Developmental psychology, 53(12), 2384-2396.

Joyce, H. D. ve Early, T. J. (2014). The impact of school connectedness and teacher support on depressive symptoms in adolescents: A multilevel analysis. Children and Youth Services Review, 39(1), 101-107. doi. 10.1016/j.childyouth.2014.02.005.

Kansky, J. ve Diener, E. (2017). Benefits of well-being: Health, social relationships, work, and resilience. Journal of Positive Psychology and Wellbeing, 1(2), 129-169.

Kim, E. K., Furlong, M. J. ve Dowdy, E. (2019). Adolescents' personality traits and positive psychological orientations: Relations with emotional distress and life satisfaction mediated by school connectedness. Child Indicators Research, Advance online publication. doi: 10.1007/s12187-019-9619-y

Kline, R. B. (2005). Principles and practice of structural equation modeling. New York: Guilford.

Koç, P. (2017). Internet addiction and subjective well-being in university students. Journal of Positive Psychology and Wellbeing, 1(1), 34-41.

Korpershoek, H., Canrinus, E. T., Fokkens-Bruinsma, M. ve de Boer, H. (2019). The relationships between school belonging and students' motivational, social-emotional, behavioural, and academic outcomes in secondary education: A meta-analytic review. Research Papers in Education. Advance online publication. doi: 10.1080/02671522.2019.1615116

Lester, L., Waters, S. ve Cross, D. (2013). The relationship between school connectedness and mental health during the transition to secondary school: A path analysis. Journal of Psychologists and Counsellors in Schools, 23(2), 157-171.

McMahon, S. D., Parnes, A. L., Keys, C. B. ve Viola, J. J. (2008). School belonging among low-income urban youth with disabilities: Testing a theoretical model. Psychology in the Schools, 45(5), 387-401.

Newman, B. M., Lohman, B. J. ve Newman, P. R. (2007). Peer group membership and a sense of belonging: Their relationship to adolescent behavior problems. Adolescence, 42(166), 241-263

Newman, B., Newman, P., Griffen, S., O'Connor, K. ve Spas, J. (2007). The relationship of social support to depressive symptoms during the transition to high school. Adolescence, 42(167), 441-459

O'Neill, F. K. (2009). Giving from our bodily belongings: Is donation an appropriate -paradigm for the giving of bodies and body parts? HEC Forum, 21(2), 151-174. doi:10.1007/s10730-009-9094-9

Osterman, K. F. (2000). Students' need for belonging in the school community. Review of Educational Research, 70(3), 323-367.

Özdemir, S., Sezgin, F., Şirin, H., Karip, E. ve Erkan, S. (2010). İlköğretim okulu öğrencilerinin okul iklimine ilişkin algılarını yordayan değişkenlerin incelenmesi. Hacettepe Üniversitesi Ĕ̆itim Fakültesi Dergisi, 38(38), 213-224.

Pate, C. M., Maras, M. A., Whitney, S. D. ve Bradshaw, C. P. (2017). Exploring psychosocial mechanisms and interactions: Links between adolescent emotional distress, school connectedness, and educational achievement. School Mental Health, 9(1), 28-43. doi: 10.1007/s12310-016-9202-3.

Phan, H. P. (2013). Antecedents and consequences of school belonging: Empirical evidence and implications for practices. Journal of Educational and Developmental Psychology, 3(2), 117-132.

Pittman, L. D. ve Richmond, A. (2007). Academic and psychological functioning in late adolescence: The importance of school belonging. The Journal of Experimental Education, 75(4), 270-290.

Ragelienė, T. (2016). Links of adolescents identity development and relationship with peers: A systematic 
literature review. Journal of the Canadian Academy of Child and Adolescent Psychiatry, 25(2), 97-105.

Renshaw, T. L. (2014). Preliminary psychometric properties of the Student Prosociality Scale, Academic Perseverance Scale, and Youth Risks and Assets Survey. Social Science Research Network (SSRN2439539): Social Science Research Network (SSRN2439539): http://papers.ssrn.com/sol3/papers.cfm?abstract_id!2439439 adresinden erişildi.

Renshaw, T. L. ve Arslan, G. (2016). Psychometric properties of the Student Subjective Wellbeing Questionnaire with Turkish adolescents: A generalization study. Canadian Journal of School Psychology, 31(2), 139-151. doi: 10.1177/0829573516634644.

Renshaw, T. L., Long, A. C. J. ve Cook, C. R. (2015). Assessing adolescents' positive psychological functioning at school: Development and validation of the student subjective wellbeing questionnaire. School Psychology Quarterly, 30(4), 534-552. doi:10.1037/spq0000088

Roeser, R. W., Midgley, C. ve Urdan, T. C. (1996). Perceptions of the school psychological environment and early adolescents' psychological and behavioral functioning in school: The mediating role of goals and belonging. Journal of educational psychology, 88(3), 408-422.

Sánchez, B., Colón, Y. ve Esparza, P. (2005). The role of sense of school belonging and gender in the academic adjustment of Latino adolescents. Journal of Youth and Adolescence, 34(6), 619-628.

Sarı, M. (2013). Lise öğrencilerinde okula aidiyet duygusu. Anadolu Üniversitesi Sosyal Bilimler Dergisi, 13(1), $147-160$.

Sarı, M. ve Özgök, A. (2014). Ortaokul öğrencilerinde okula aidiyet duygusu ve empatik sınıf atmosferi alg1s1. Gaziantep University Journal of Social Sciences, 13(2), 479-492.

Schmitt, N., Oswald, F. L., Friede, A., Imus, A. ve Merritt, S. (2008). Perceived fit with an academic environment: Attitudinal and behavioral outcomes. Journal of Vocational Behavior, 72(3), 317-335.

Springer, J. M. (2012). Acceptance and commitment therapy: Part of the "Third Wave" in the behavioral tradition. Journal of Mental health Counseling, 34(3), 205-212.

Stuntz, C. P. (2017). Linking positive psychology and the transtheoretical model: How character strengths and processes of change relate to each other and to exercise. Journal of Positive Psychology and Wellbeing, 1(2), $85-108$.

Sumi, K. (2017). Reliability and construct validity of the Gratitude Questionnaire 6 Item Form (GQ 6) in a sample of Japanese college students. Journal of Positive Psychology and Wellbeing, 1(2), 73-84.

Tanhan, A. (2018). Beginning counselors' supervision in counseling and challenges and supports they experience: Based on developmental models. Adryaman Üniversitesi Ĕ̆itim Bilimleri Dergisi, 8(1), 49-71.

Tanhan, A. (2019). Acceptance and commitment therapy with ecological systems theory: Addressing Muslim mental health issues and wellbeing. Journal of Positive Psychology and Wellbeing. Advance online publication. http://journalppw.com/index.php/JPPW/article/ view/172 adresinden erişildi.

Tanhan, A. ve Francisco, V. T. (2019). Muslims and mental health concerns: A social ecological model perspective. Journal of Community Psychology, 47(4), 964-978. doi:10.1002/jcop.22166

Telef, B. B. (2017). Positive psychology in Turkey: A review study of postgraduate theses. Journal of Positive Psychology and Wellbeing, 1(1), 42-52.

Tian, L., Zhang, L., Huebner, E. S., Zheng, X. ve Liu, W. (2016). The longitudinal relationship between school belonging and subjective well-being in school among elementary school students. Applied Research in Quality of Life, 11(4), 1269-1285.

Yıldırım, A. (1997). Gender role influences on Turkish Adolescent' self-identity. Adolescence, 32(125), 217-231. 


\section{EXTENDED ABSTRACT}

\section{Introduction}

School has a central position in the daily life of adolescents, and the adolescents spend a great part of their time in the school setting (Arslan \& Duru, 2017). Some students perceive themselves as a meaningful part of the school in this process, and they have more positive feelings and attitudes toward school (Arslan, 2016). This perception of the student being valued and supported by others at school is conceptualized as school belonging (Goodenow \& Grady 1993; Osterman, 2000). School belonging is that a student considers himself/herself as a meaningful, important and valuable part of the school (Arslan \& Duru, 2017). In addition to these two approaches that are originates more from an individual/intrapsychic perspective, belonging and have connection with others plays a central role in Ecological Systems Theory, EST, (Bronfenbrenner, 1977; Tanhan \& Francisco, 2019). Previous research- utilized or just mentioned SDT, ACT, and/or EST perspectives - revealed that school belonging is a significant factor associated with student positive academic, social and emotional outcomes (e.g., Anderman 2003; Arslan \& Duru, 2017; Deci \& Ryan 1991; Goodenow 1993; Goodenow \& Grady, 1993; Osterman, 2000; Tanhan \& Francisco, 2019). For example, students with high school belonging reported better academic achievement, higher academic motivation, and lower school absenteeism (Adelabu 2007; Babakhani 2014; Booker, 2006; Phan, 2013; Gillen-O'Neel \& Fuligni, 2013). Specifically, many studies have stated the association between school belonging and student academic achievement, and they have indicated students with high academic achievement reported higher sense of school belonging than those with low academic achievement (Anderman, 2002; Booker, 2006; Goodenow \& Grady, 1993; Pittman \& Richmond, 2007; Sar1, 2013). In addition, longitudinal outcomes have supported these findings, revealing that school belonging is closely associated with youth school functioning and adjustment outcomes (Gillen-O'Neel \& Fuligni, 2013; McMahon, Parnes, Keys \& Viola, 2008). In addition to the effects of school belonging on youth school functioning, studies have demonstrated that students with high levels of school belonging exhibit lower psychological problems, such as internalizing and externalizing problems (Altınsoy \& Özyer, 2018; Booker 2006; Osterman, 2000; Pittman \& Richmond 2007; Tanhan \& Francisco, 2019). For example, high school belonging was found to be associated with high self-esteem (Duru, 2015; Hernández, Robins, Widaman \& Conger, 2017), lower violent tendency (Balkıs, Duru, \& Buluş, 2005), and less internalizing an externalizing problems (Anderman, 2002; Bond et al., 2007). Specifically, students who perceive themselves as excluded or rejected at school reported more emotional and behavioral problems as well as lower wellbeing and academic outcomes (Arslan, 2018a). Although there has been a significant increase in studies of school belonging in recent years, research examining the effect of school belonging on adolescents' psychological adjustment and school functioning have been quite limited. The present study investigated the effects of school belonging on school functioning and psychological adjustment problems in adolescents grounded in selfdetermiantion theory, acceptance and commitment therapy, and ecological systems theory.

\section{Method}

Sample of the study comprised of 333 adolescents from a middle and high school, with ranging in age between 11 and 18 years (Mean = 15.45; SD=1.75). Participants were 55.9\% (186) female and 44.1\% (147) male from two state schools in western part of Turkey. Students' sense of school belonging was measured using the School Belongingness Scale (SBS), and Youth Internalizing and Externalizing Behavior Screener (YIBS; YEBS) were used to assess youth psychological adjustment problems. Moreover, student school functioning was measured using the Students Subjective Wellbeing Questionnaire, Academic Satisfaction Scale, Student Prosociality Scale, and self-report academic achievement. Data analyses were conducted in two steps. Firstly, observed scale characteristics, normality assumption, and correlation analysis were performed. Skewness and kurtosis scores were used to assess normality of the variables. Correlation analysis was conducted to examine the relationships between variables. Following, path analysis was performed to test the effect of the school belonging on adolescent psychological adjustment problems and school functioning. All data analyses were conducted using SPSS 25 and AMOS version 24. 


\section{Results}

Findings from observed scale characteristics indicated that all variables had relatively normal distribution. Additionally, the results showed that the internal reliability of the scale with present sample were adequateto-strong, see Table 1. Following, correlation analysis was conducted, demonstrating that school belonging was significantly and positively associated with students' school functioning ( $r$ range $=.15$ to .45 ) and negatively related to their internalizing and externalizing problems $(r=-.39$ and -.43$)$. Finally, path analysis outcomes indicated that school belonging significantly predicted all variables. School belonging significantly and positively predicted students' school achievement, joy of learning, educational purpose, academic efficacy, academic satisfaction, and prosocial behaviors ( $\beta$ range $=.16$ to .60$)$. Furthermore, the results demonstrated that school belonging significantly and negatively predicted internalizing and externalizing problems in adolescents $(\beta=-.38$ and -.51$)$. School belonging has a strong effect size on all variables except for academic achievement (see Figure 1).

\section{Conclusion}

The present study investigated the association between school belonging and school functioning and psychological adjustment problems in adolescents. Correlation analysis results revealed that school belonging increases while internalizing and externalizing problems decrease and there is a significant increase in school functions. Path analysis outcomes indicated that school belonging significantly predicted all variables. School belonging significantly and positively predicted students' school achievement, joy of learning, educational purpose, academic efficacy, academic satisfaction, and prosocial behaviors. Furthermore, the results demonstrated that school belonging significantly and negatively predicted internalizing and externalizing problems in adolescents. The outcomes provide further evidence, indicating that school belonging has a crucial role in youth school functioning and healthy development. Therefore, school consolers or other mental health providers could promote student sense of belonging at schools to decrease psychological problems and increase positive outcomes at school setting. 